\title{
RUKHSAH (KERINGANAN) BAGI ORANG SAKIT DALAM PERSPEKTIF HUKUM ISLAM
}

Oleh: H. Mahmudin, Lc,. M.H.

\begin{abstract}
Abstrak
Dalam perspektif hukum Islam orang yang sakit tetap berkewajiban menjalankan agamanya, selama akalnya masih berfungsi dengan baik (tidak gila), baik kewajiban kepada Allâh ataupun yang berkaitan dengan hak-hak manusia, tetapi aktivitas orang sakit tentunya berbeda dengan orang yang sehat. Syariah Islam memberikan beberapa kemudahan bagi orang yang sakit. Hal ini bertujuan agar orang yang sakit tetap melaksanakan ibadah sesuai dengan kondisi sakit yang dideritanya tanpa beban dan kesulitan. Rukhsah (keringanan) yang diberikan oleh syariat Islam kepada orang yang sakit seperti: bolehnya berbuka puasa pada saat sakit, ataupun melakukan salat dengan posisi yang mampu dilaksanakannnya dan yang lainnya.
\end{abstract}

Kata Kunci : Hukum Islam, Rukhsah, Orang Sakit.

\section{A. Pendahuluan}

Dalam perspektif Islam, setiap penyakit merupakan cobaan yang diberikan oleh Allâh SWT kepada hamba-Nya untuk menguji keimanannya.

Sakit juga dapat dipandang sebagai peringatan dari Allâh SWT untuk mengingatkan segala dosa-dosa akibat perbuatan jahat yang dilakukannya selama hidupnya. Pada kondisi sakit, kebanyakan manusia baru mengingat dosa-dosa dari perbuatan jahatnya dimasa lalu. Dalam kondisi sakit itulah, kebanyakan manusia baru melakukan taubat dengan cara memohon ampunan kepada Allâh SWT dan berjanji tidak akan mengulangi perbuatan jahatnya di kemudian hari.

Jadi, sudah selayaknya bagi setiap mu`min untuk kemudian bertambah imannya saat ujian itu datang, termasuk di dalamnya adalah ujian sakit yang merupakan bagian dari ujian yang menimpa jiwa. 
H. Mahmudin, Lc., M.H: Rukhsah (Keringan) Bagi Orang Sakit Dalam Perspektif Hukum Islam

Jangan sampai menjadi seperti orang-orang munafiq yang tidak mau bertaubat atau mengambil pelajaran saat mereka diuji oleh Allâh subhanahu wa ta'ala, QS. At-Tawbah/9: 126.

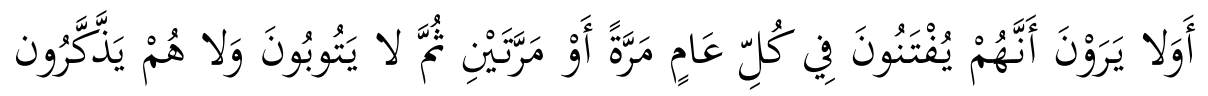

Artinya: "Dan tidaklah mereka memperhatikan bahwa mereka diuji sekali atau dua kali setiap tahun, dan mereka tidak (juga) bertaubat dan tidak (pula) mengambil pelajaran?"

Dalam perspektif Islam orang yang sakit tetap berkewajiban menjalankan agamanya, selama akalnya masih berfungsi dengan baik yakni tidak gila, baik kewajiban kepada Allâh seperti melaksanakan salat, puasa, membayar zakat, ataupun yang berkaitan dengan hak-hak manusia seperti wajibnya hukuman qhisas atau wajib memberikan nafkah kepada istri dan orang yang menjadi tanggungannya. Demikian juga semua aktivitasnya berlaku seperti orang sehat, seperti ucapan talaq, jual beli dan pemberiannya. ${ }^{1}$

Kemudahan merupakan salah satu prinsip penting dalam Islam. Ia merupakan anugerah Allâh SWT, diberikan agar manusia tetap bersemangat dan tekun dalam menjalankan ajaran agama, terutama dalam situasi sulit. Sebagaimana firman Allâh SWT. Q.S. al-Baqarah/2: 185.

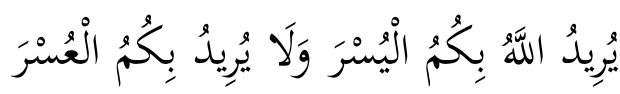

Artinya: "Allâh menghendaki kemudahan bagimu dan tidak menghendaki kesukaran bagimu”

1 Abdul 'Aziz bin Muhammad Al-Bukhâry,. Ushul Fakhru al-Islam bî Hâmisy Kasyful Asyrar. Jilid. 4. (Beirut: Dâr al-Kitâb al-'Araby. 1974), hal. 307.

Jurnal Ilmiah Al QALAM, Vol. 11, No. 23, Januari-Juni 2017 
H. Mahmudin, Lc., M.H: Rukhsah (Keringan) Bagi Orang Sakit Dalam Perspektif Hukum Islam

Berdasarkan dalil di atas, Allâh Swt memberikan keringanan bagi yang mempunyai udzur dalam menunaikan ibadah sesuai dengan sakit atau udzur yang mereka alami, supaya mereka dapat menunaikan ibadah kepada Allâh SWT tanpa mengalami beban dan kesulitan.

Misalnya salat yang dilakukan oleh orang yang sehat tentu berbeda dengan posisi salat orang yang sedang sakit, syariah Islam memberikan kemudahan bagi mereka yang sedang mengalami sakit dengan diperbolehkannya melakukan salat dengan posisi duduk apabila tidak mampu berdiri, kemudian boleh berbaring ketika tidak mampu untuk duduk. Sebagaiamana riwayat hadits 'Imrân bin Hushain dan ijma' para ulama.

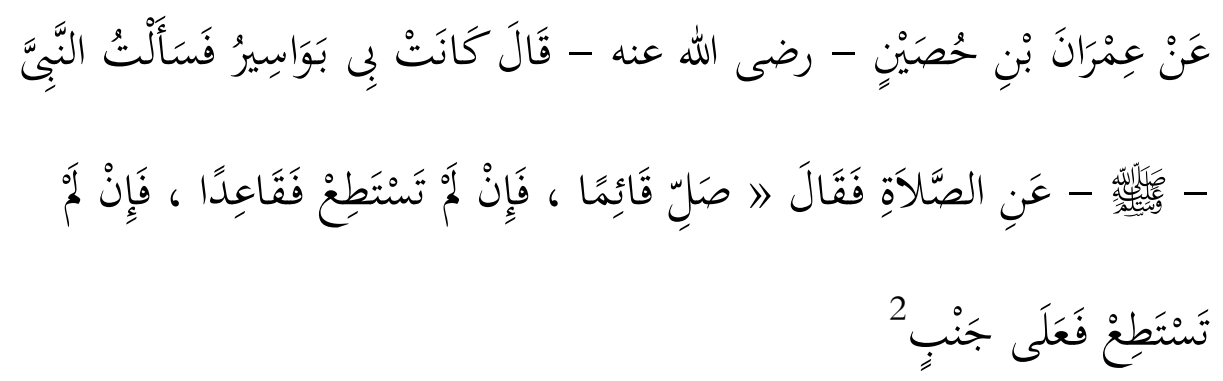

Artinya: "Dari Imrân bin Hushain ra. Berkata: Pernah penyakit wasir menimpaku, lalu aku bertanya kepada Nabi ShallAllâhu 'alaihi wa sallam tentang cara shalatnya. Maka beliau ShallAllâhu 'alaihi wa sallam menjawab: Shalatlah dengan berdiri, apabila tidak mampu, maka duduklah dan bila tidak mampu juga maka berbaringlah”.

Dalam makalah ini penulis akan menjelaskan hal yang berkaitan dengan sakit, kriteria orang sakit yang mendapat rukhshah (keringanan)

${ }^{2}$ Al-Bukhâry, Muhammad bin Ismail, Shahîh al-Bukhâry, Beirut: Dâr al-Jail, t.th. jilid 2, h. 60. Dan Muhammad bin Yazid Ibnu Majah. Sunan Ibnu Majah. Jilid 1 (Beirut: al-Maktabah al-'Ilmiah. t.th), hal. 386.

Jurnal Ilmiah Al QALAM, Vol. 11, No. 23, Januari-Juni 2017 
H. Mahmudin, Lc., M.H: Rukhsah (Keringan) Bagi Orang Sakit Dalam Perspektif Hukum Islam

serta rukhsah (keringanan) bagi orang yang sakit dalam melaksanakan ibadah kepada Allâh Swt.

\section{B. Pembahasan}

\section{Pengertian Maradl (sakit)}

Dalam bahasa arab disebut maradl (sakit) terdiri dari tiga kata yaitu, mim, ra dan dhad, kata al-maradl merupakan sinonim dari kata as-saqham lawan dari as-shihah (sehat). ${ }^{3}$

Secara isthilah Maradl menurut al-Jurjâny yaitu:

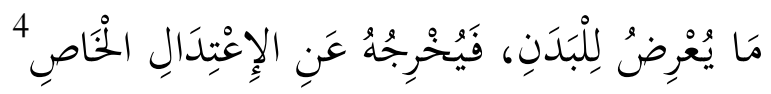

Artinya: "Sesuatu yang menimpa badan, sehingga menyebabkan dia terganggu”.

Dalam kamus bahasa Indonesia kata sakit berarti: berasa tidak nyaman di tubuh (bagian tubuh) karena menderita sesuatu (demam, sakit perut, dan sebagainya). ${ }^{5}$

Adapun definisi sakit secara umum yaitu: Penyakit adalah suatu keadaan abnormal dari tubuh atau pikiran berupa gangguan dalam fungsi normal individu sebagai totalitas yang menyebabkan ketidaknyamanan disfungsi atau kesukaran terhadap orang yang

\footnotetext{
${ }^{3}$ Ibnu Manzûr. Lisan al- 'Arab. jilid 7 (Qaherah: al-Mu'asasah al-Mhisriyah. t.th.), hal. 331 .

${ }^{4}$ Al-Jurjânîy, Ali bin muhammad. al-Ta'rîfât. Teheran: Dâr Kutub al'Ilmiyah. t.th. h. 92.

${ }^{5}$ http://bahasa.cs.ui.ac.id/kbbi/kbbi.php?keyword=sakit\&varbidang=all\&vard ialek=all\&varragam=all\&varkelas=all\&submit=tabel/18 November 2014, 20:30 PM
}

Jurnal Ilmiah Al QALAM, Vol. 11, No. 23, Januari-Juni 2017 
H. Mahmudin, Lc., M.H: Rukhsah (Keringan) Bagi Orang Sakit Dalam Perspektif Hukum Islam

dipengaruhinya yang menyebabkan aktivitas kerja atau kegiatannya terganggu. ${ }^{6}$

\section{Dalil-Dalil Keringanan Bagi Orang Yang Sakit.}

Sakit merupakan salah satu sebab adanya keringanan dalam syariat. Dalam al-Quran dan Hadist banyak ditemukan keterangan tentang keringanan bagi orang yang sakit di antaranya adalah:

Firman Allâh SWT Q.S. al-Baqarah/2: 184.

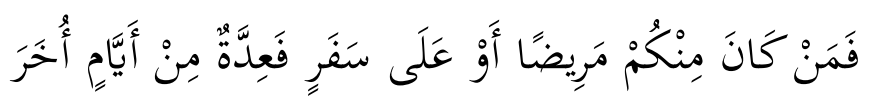

Artinya: "Maka barangsiapa diantara kamu ada yang sakit atau dalam perjalanan (lalu ia berbuka), Maka (wajiblah baginya berpuasa) sebanyak hari yang ditinggalkan itu pada hari-hari yang lain”.

Firman Allâh SWT Q.S. al-Baqarah/2: 196.
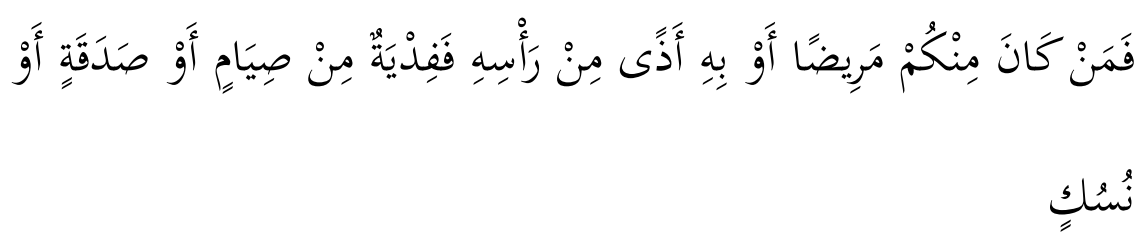

Artinya: "Jika ada di antaramu yang sakit atau ada gangguan di kepalanya (lalu ia bercukur), Maka wajiblah atasnya berfid-yah, yaitu: berpuasa atau bersedekah atau berkorban".

${ }^{6}$ http://haegi13.wordpress.com/2014/03/22/sakit-menurut-para-ahli/18 November 2014, 20:30 PM.

Jurnal Ilmiah Al QALAM, Vol. 11, No. 23, Januari-Juni 2017 
H. Mahmudin, Lc., M.H: Rukhsah (Keringan) Bagi Orang Sakit Dalam Perspektif Hukum Islam

Firman Allâh SWT Q.S. an-Nisâ/4: 43.

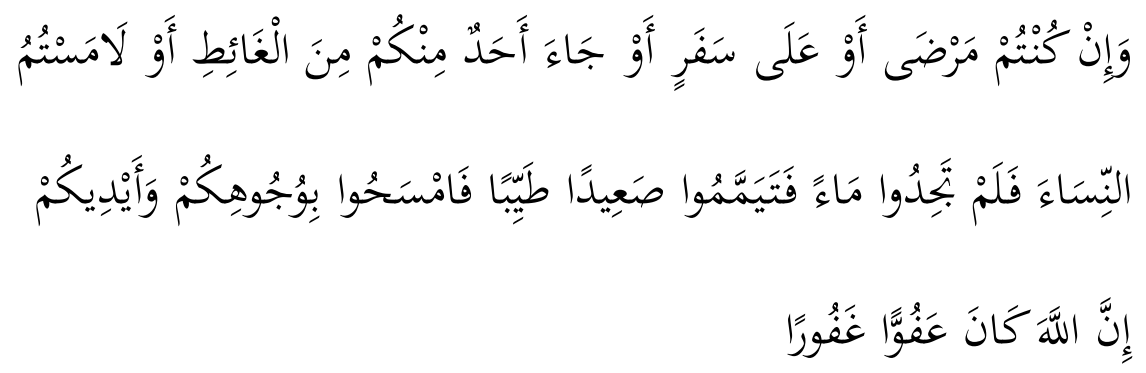

Artinya: "Dan jika kamu sakit atau sedang dalam musafir atau datang dari tempat buang air atau kamu Telah menyentuh perempuan, Kemudian kamu tidak mendapat air, Maka bertayamumlah kamu dengan tanah yang baik (suci); sapulah mukamu dan tanganmu. Sesungguhnya Allâh Maha Pema'af lagi Maha Pengampun”.

Firman Allâh SWT Q.S. an-Nisâ/4:102.

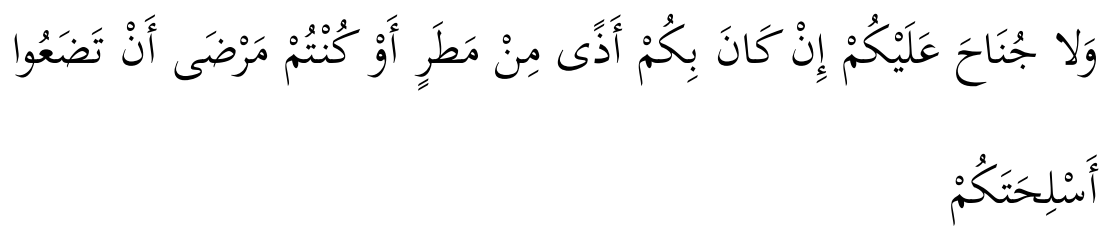

Artinya: "Dan tidak ada dosa atasmu, jika kamu mendapat sesuatu kesusahan Karena hujan atau Karena kamu memang sakit; meletakkan senjata-senjatamu”.

Sabda Rasûlullâh SAW:

Jurnal Ilmiah Al QALAM, Vol. 11, No. 23, Januari-Juni 2017 
H. Mahmudin, Lc., M.H: Rukhsah (Keringan) Bagi Orang Sakit Dalam Perspektif Hukum Islam
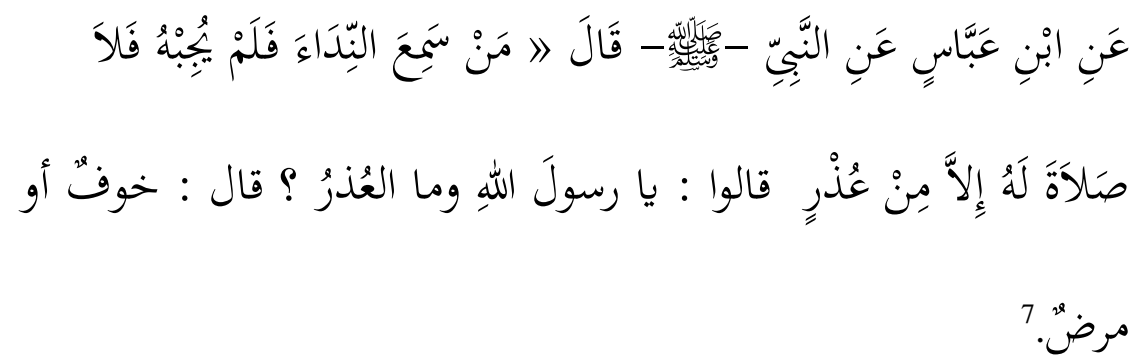

Artinya: "Dari Ibnu Abbas dari Nabi Saw bersabda: barangsiapa yang mendengar azan dan dia tidak memenuhi panggilan itu maka salatnya kurang sempurna, kecuali bagi orang yang uzur, sahabat bertanya apakah yang dimaksud dengan uzur. Rasulullah Saw bersabda: rasa takut dan sakit”.

Berdasarkan dalil-dalil di atas, Allâh SWT memberikan keringanan bagi yang sakit dalam menunaikan ibadah sesuai dengan sakit atau yang mereka alami, supaya mereka dapat menunaikan ibadah kepada Allâh SWT tanpa mengalami beban dan kesulitan.

Para ulama sepakat bahwa orang sakit akan mendapatkan keringanan apabila dalam menjalankan ibadah itu akan bertambah sakit, lambat sembuhnya atau menyebabkan kerusakan pada anggota badannya. ${ }^{8}$

\section{Kriteria orang sakit yang mendapat rukhshah (keringanan).}

${ }^{7}$ Sulaiman bin al-Asy'as Abû Dâud, Sunan Abî Dâud, jilid 1, (Beirut: Dâr alFikr, t.th), hal. 151.

${ }^{8}$ Izzuddin Abdul Aziz Ibn 'Abdi Salam, Qawâed al-Ahkâm fî mashâlih alAnam. jilid 2, (Beirut: Dâr al-Kutûb al-'Ilmiyah. t.th), h. 10. Lihat juga: Jalal ad-Dîn Abdurrahman As-Suyûthi, al-Asybah wa an-Nazdair. (Beirut: al-Maktabah asy'Ariyah. 2003), h. 91. Syihabuddin Ahmad bin Idris Al-Qarâfy, al- Furuq, jilid 1 (Beirut: 'Alim al-Kitab, t.th.), hal. 118.

Jurnal Ilmiah Al QALAM, Vol. 11, No. 23, Januari-Juni 2017 
H. Mahmudin, Lc., M.H: Rukhsah (Keringan) Bagi Orang Sakit Dalam Perspektif Hukum Islam

Orang yang sakit tetap ada taklif (beban) untuk mengerjakan perintah dan menjauhi larangan, tetapi keadaan orang sakit berbeda dengan orang yang sehat dipandang dari dua segi:

a. Kewajibannya mengerjakan ibadah sesuai dengan kemampuannya. Sebagaimana telah dijelaskan sebelumnya dalil dari al-Quran dan Sunnah tentang keringanan bagi orang yang sakit.

Para ulama berbeda pendapat tentang kriteria orang sakit yang mendapat rukhshah (keringanan), di antaranya:

1) Jumhur ulama berpendapat: "Kriteria orang sakit yang mendapat rukhshah adalah seseorang yang menderita sakit keras, yakni ketika seseorang melakukan ibadah maka sakitnya akan bertambah parah atau kesembuhannya tertunda". 9

2) Ahli Dzahir berpendapat: ${ }^{10}$ "Kriteria orang sakit yang mendapat rukhshah adalah sakit apapun yang menimpanya. Walaupun hanya sakit ibu jari, sakit gigi atau perut."

Ahlu Dzahir berargumen, karena ayat yang menjelaskan keringanan bagi orang sakit bersifat umum yakni apapun jenis sakitnya".

Seperti firman Allâh SWT dalam Q.S. al-Baqarah/2: 196.

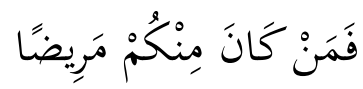

${ }^{9}$ Adnan Muhammad 'Amâmah, Al-Ihkâm wa Takrîr (Beirut: Muasasah alRisâlah, 2004M), hal. 87.

${ }^{10}$ Muhammad bin Ahmad Ibnu Rusyd. Bidayah al-Mujtahid wa Nihâyah alMuqthasid. cet. V. jilid 1 (Beirut: Dâr al-Ma'rifah. 1981 M), h. 297. Muhammad bin Ahmad Al-Qhurtuby, al-Jâmi' lî al-Ahkâm al-Quran, jilid 2, (Beirut: Dâr Ihyâ atTurâts, 1952M), hal. 276.

Jurnal Ilmiah Al QALAM, Vol. 11, No. 23, Januari-Juni 2017 
H. Mahmudin, Lc., M.H: Rukhsah (Keringan) Bagi Orang Sakit Dalam Perspektif Hukum Islam

Artinya: "Jika ada di antaramu yang sakit"

3) Apabila seseorang sakit yang sangat parah dan tidak ada harapan sembuhnya (sakit yang membawa kematian). ${ }^{11}$ Maka sejak mulai sakitnya itu menyebabkan dia al-hajru (tidak berlaku) segala transaksi atau aktivitas yang berkaitan dengan hartanya. Hal ini bertujuan untuk menjaga hak ahli waris dan orang yang pernah memberikan pinjaman kepada orang yang sakit tersebut. Oleh karena itu maka tidak diperbolehkan melaksanakan wasiat yang dilakukan pada saat sakit sebelum menunaikan kewajibannya untuk membayar utang piutang. Dan tidak boleh melaksanakan wasiatnya lebih dari sepertiga hartanya.

\section{Kemudahan Islam Bagi Orang Yang Sakit.}

Allâh SWT memberikan keringanan bagi yang mempunyai uzur dalam menunaikan ibadah sesuai dengan sakit atau yang mereka alami, supaya mereka dapat menunaikan ibadah kepada Allâh SWT tanpa mengalami beban dan kesulitan.

Di antara keringanan bagi orang sakit sebagai berikut:

a. Bertayamum.

Orang yang sedang sakit, wajib bersuci dengan menggunakan air, berwudhu untuk menghilangkan hadast kecil, dan mandi untuk menghilangkan hadast besar. Jika tidak mampu menggunakan air atau khawatir penyakit yang diderita akan semakin berat atau khawatir tertunda kesembuhannya, maka boleh bertayamum. Adapun sakit yang tidak membahayakan bagi tubuh maka tidak ada keringanan dalam

${ }^{11}$ Al-Bukhâry, Kasyfu al-Asrar... jilid 4, hal. 311.

Jurnal Ilmiah Al QALAM, Vol. 11, No. 23, Januari-Juni 2017 
H. Mahmudin, Lc., M.H: Rukhsah (Keringan) Bagi Orang Sakit Dalam Perspektif Hukum Islam

bertayamum. Untuk lebih jelas Para ulama membagi sakit kepada tiga bagian. Yaitu:

1) Sakit parah

Sakit yang sangat parah yaitu keadaan sakit yang tidak dibolehkan menggunakan air seperti akan membahayakan bagi anggota tubuh, memperlambat sembuhnya atau penyakitnya akan bertambah parah sehingga menyebabkan kematian. Para imam empat mazhab: Imam Abû Hanifah, ${ }^{12}$ Imam Malik, ${ }^{13}$ Imam asSyafi' $i,{ }^{14}$ dan Imam Ahmad, sepakat bahwa dalam keadaan seperti ini seseorang dibolehkan untuk bertayamum. Dengan landasan firman Allâh Q.S. an-Nisâ/4: 43.

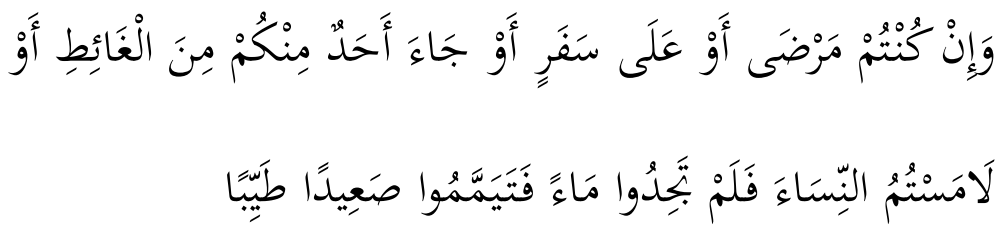

Artinya: "Dan jika kamu sakit atau sedang dalam musafir atau datang dari tempat buang air atau kamu Telah menyentuh perempuan, Kemudian kamu tidak mendapat air, Maka bertayamumlah kamu dengan tanah yang baik (suci);

Dan Firman Allâh Swt. Q.S. al-Hâj/22:78.

${ }^{12}$ Al-Kâsany, 'Alauddin bin Mas'ud. Badâ 'iu Shanâ 'i. cet. II. jilid 1 (Dâr alKitâb al-'Arab Lebanon: Beirut. 1982 M), hal.48. hal. 45 .

${ }^{13}$ Imam Malik, Al-Mudawwanah al-Kubrâ, jilid 2 (Mathba'ah Sa'adah, t.th),

${ }^{14}$ As-Syairâzy. al-Muhazdab fì Fiqh al-Imâm as-Syâfi'i. jilid 1 (Beirut: Dâr al-Ma'rifah. t.th), hal. 35 .

Jurnal Ilmiah Al QALAM, Vol. 11, No. 23, Januari-Juni 2017 
H. Mahmudin, Lc., M.H: Rukhsah (Keringan) Bagi Orang Sakit Dalam Perspektif Hukum Islam

$$
\text { وَمَا جَعَلَ عَلَنْكُمْ فِي الدِيِينِ مِنْ حَرَج }
$$

Artinya: "Dan Dia sekali-kali tidak menjadikan untuk kamu dalam agama suatu kesempitan”.

Dan Firman Allâh Swt. Q.S. an-Nisâ/4 :29.

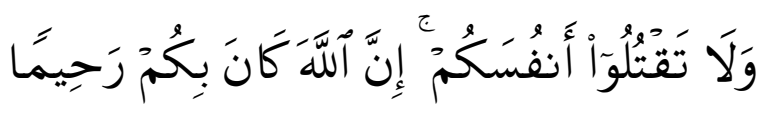

Artinya: "Dan janganlah kamu membunuh dirimu.

Sesungguhnya Allâh adalah Maha Penyayang kepadamu".

Pendapat ini juga diperkuat riwayat dari Abdullah bin

Abbas mengatakan:

$$
\begin{aligned}
& \text { عَنْ عَبْدَ اللَّهِ بْنَ عَبَّاسِ قَالَ أصَابَ رَجُلَا جُجْحُ في عَهْدِ رسول اللَّهِ }
\end{aligned}
$$

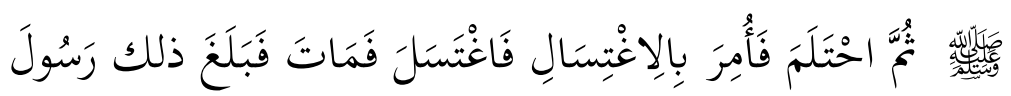

$$
\begin{aligned}
& \text { اللَّهِ } 15
\end{aligned}
$$

Artinya: "Dari Abdullah bin Abbas mengatakakan: Ada seorang sahabat yang sedang terluka di kepalanya akibat perang, ketika itu dia sedang junub. Sahabat tersebut kemudian bertanya kepada sahabat yang

${ }^{15}$ Sulaiman bin As'as, Sunan Abû Dâud, jilid 1, (Beirut: Dâr Fikr, t.th), h. 93. Lihat juga: Muhammad bin Yazid, Sunan Ibnu Mâjah, jilid 1, (Beirut: al-Maktabah al-'Ilmiyah, t.th), h. 189. Dan Abdullah bin Abdurrahman Ad-Dâramy, Sunan AdDâramy, jilid 2, (Beirut: Dâr al-Maktabah al-'Ilmiyah, t.th), hal. 192.

Jurnal Ilmiah Al QALAM, Vol. 11, No. 23, Januari-Juni 2017 
H. Mahmudin, Lc., M.H: Rukhsah (Keringan) Bagi Orang Sakit Dalam Perspektif Hukum Islam

lain tentang keringanan baginya untuk tidak menggunakan air, Namun para sahabat tidak memberikan keringanan baginya, sehingga dia mandi dan akhirnya meninggal dunia, beriata itu sampai kepada Rasûlullâh ShalAllâhu Alaihi Wasalam dan beliau mendo'akan kepada sahabat yang tidak memberikan keringanan dengan do'a: "Mereka membunuhnya, semoga Allâh membunuh mereka, bukankah obat bagi orang yang tidak tahu adalah bertanya"

2) Sakit sedang (tidak terlalu parah)

Yaitu kondisi sakit yang dirasakan tidak terlalu parah, tetapi ketika menggunakan air ada kekhawatiran yang akan menyebabkan bertambahnya penyakit atau lambatnya sembuh. Dalam kondisi ini menurut mazhab jumhur ulama (Imam Abu Hanifah, Imam Malik ${ }^{16}$ dan pendapat kedua Imam Syafi'i ${ }^{17}$ membolehkan untuk bertayamum.

\section{3) Sakit ringan}

Yaitu kondisi sakit yang dirasakan tidak akan membahayakan dalam penggunaan air sebagai alat untuk bersuci. Tidak ada kekhawatiran bertambahnya penyakit atau lamanya kesembuhan. Seperti sakit kepala, sakit gigi, sakit hal. 45 .

${ }^{16}$ Imam Malik, Al-Mudawanah al-Kubrâ, jilid ( Mathba'ah Sa'ada, t.th) 2 ${ }^{17}$ As-Syairazy, al-Muhazdab, jilid 1 hal. 35.

Jurnal Ilmiah Al QALAM, Vol. 11, No. 23, Januari-Juni 2017 
H. Mahmudin, Lc., M.H: Rukhsah (Keringan) Bagi Orang Sakit Dalam Perspektif Hukum Islam

perut, demam. Dalam kondisi seperti ini para ulama sepakat tidak ada keringanan dalam bertayamum. ${ }^{18}$

b. Melaksanakan salat dengan posisi yang memungkinkan ketika tidak mampu berdiri

Orang yang sakit tetap wajib mengerjakan shalat pada waktunya dan melaksanakannya menurut kemampuannya. Dalam syariat Islam ada cara khusus yang dilakukan oleh orang yang sakit ketika tidak mampu berdiri.

Tata cara shalat bagi orang sakit adalah sebagi berikut :

Diwajibkan bagi orang yang sakit untuk shalat dengan berdiri apabila mampu dan tidak khawatir sakitnya bertambah parah, karena berdiri dalam shalat wajib merupakan rukun shalat. Allâh Azza wa Jalla berfirman : al-Baqarah/ 2:238.

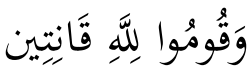

Artinya: "Berdirilah untuk Allâh (dalam shalatmu) dengan khusyu"

Orang sakit yang tidak mampu berdiri, maka ia melakukan shalatnya dengan duduk, berdasarkan hadits 'Imrân bin Hushain dan ijma' para ulama.

$$
\begin{aligned}
& \text { عَنْ عِمْرَانَ بْنِ حُصَيْنِ - رضى الله عنه - قَالَ كَانَتْ بِى بَوَاسِيرُ فَسَأَلْتُ }
\end{aligned}
$$

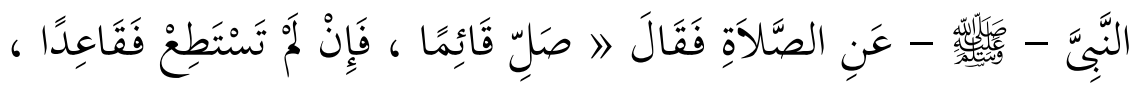

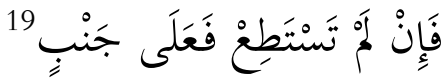
t.th) hal. 284 .

${ }^{18}$ Muhyiddin An-Nawawy, al-Majmu', jilid 2 (Mesir: Syirkah al-'Ulama, Jurnal Ilmiah Al QALAM, Vol. 11, No. 23, Januari-Juni 2017 
H. Mahmudin, Lc., M.H: Rukhsah (Keringan) Bagi Orang Sakit Dalam Perspektif Hukum Islam

Artinya: "Dari 'Imrân bin Hushain Pernah penyakit wasir menimpaku, lalu aku bertanya kepada Nabi ShallAllâhu 'alaihi wa sallam tentang cara shalatnya. Maka beliau ShallAllâhu 'alaihi wa sallam menjawab: Shalatlah dengan berdiri, apabila tidak mampu, maka duduklah dan bila tidak mampu juga maka berbaringlah"

c. Menjama' salat

Apabila melakukan shalat pada waktunya terasa berat bagi orang yang sakit, maka diperbolehkan menjamâ' (menggabung) shalat, shalat Zhuhur dan Ashar, Maghrib dan 'Isya' baik dengan jamâ' taqdîm atau ta'khîr, dengan cara memilih yang termudah baginya. Sedangkan shalat Shubuh maka tidak boleh dijama' karena waktunya terpisah dari shalat sebelum dan sesudahnya. Di antara dasar kebolehan ini adalah hadits Ibnu Abas RadhiyAllâhu 'anhuma yang berbunyi :

$$
\begin{aligned}
& \text { عَنْ ابن عباس قَالَ : (( جمع رَسُوْل الله بَيْنَ الظهر والعصر ، وبين } \\
& \text { المغرب والعشاء بالمدينة من غَيْر خوف ولا مطر ـ فقيل لابن عباس: ما } \\
& \text { أراد بذلك ؟ قَالَ: أراد أن لا يهرج أمته ) }
\end{aligned}
$$

Artinya: "Dari Ibnu Abas RadhiyAllâhu 'anhuma berkata: Rasulullah ShallAllâhu 'alaihi wa sallam telah menjama' antara Zhuhur dan Ashar, Maghrib dan Isya' di kota Madinah tanpa sebab takut dan hujan. Ditanyakan kepada Ibnu Abas RadhiyAllâhu 'anhu :

${ }^{19}$ Al-Bukhâry, Shahih al-Bukhâry, jilid 2, h. 60. Dan Ibnu Majah, Sunan Ibnu Mâjah, jilid 1, hal. 386.

${ }^{20}$ Muslim, Shahih Muslim, jilid 2, hal. 102.

Jurnal Ilmiah Al QALAM, Vol. 11, No. 23, Januari-Juni 2017 
H. Mahmudin, Lc., M.H: Rukhsah (Keringan) Bagi Orang Sakit Dalam Perspektif Hukum Islam

Mengapa beliau berbuat demikian? Beliau
RadhiyAllâhu 'anhu menjawab: Agar tidak
menyusahkan umatnya."

Dalam hadits di atas jelas Rasulullah ShallAllâhu 'alaihi wa sallam membolehkan seseorang menjamâ' shalat karena adanya rasa berat yang menyusahkan (Masyaqqah) dan sakit adalah Masyaqqah.

d. Gugur kewajiban Salat berjamaah dan Salat Jumat.

Orang sakit yang merasa berat untuk melaksanakan shalat berjama`ah dan salat Jum'at atau ia khawatir akan menambah dan atau memperlambat kesembuhannya jika shalat di masjid, maka dibolehkan tidak shalat berjama'ah. Pendapat ini didasari dari hadist yang menceritakan keadaan Nabi Saw ShallAllâhu 'alaihi wa sallam ketika sakit tidak hadir di Masjid padahal Rumah Nabi saw berada di samping Masjid. ${ }^{21}$ Pada saat itu Nabi Saw bersabda:

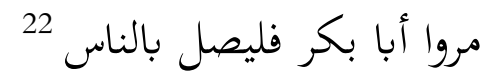

Artinya: "Perintahkan Abu Bakar RadhiyAllâhu 'anhu agar mengimami shalat”

e. Boleh berbuka puasa apabila puasa tersebut membahayakan dirinya.

\footnotetext{
${ }^{21}$ As-Syairazy, al-Muhazdab, jilid 1, hal. 101.

${ }^{22}$ Muhammad bin Idris As-Syafi' $\mathrm{i}$, al- 'Um, jilid 1 (Beirut: Dâr al-Ma'rifah, t.th), hal.138.
}

Jurnal Ilmiah Al QALAM, Vol. 11, No. 23, Januari-Juni 2017 
H. Mahmudin, Lc., M.H: Rukhsah (Keringan) Bagi Orang Sakit Dalam Perspektif Hukum Islam

Allâh Swt memberikan keringanan kepada orang yang sakit untuk tidak berpuasa, sebagai rahmat bagi mereka. para ulama sepakat bahwa sakit yang diperbolehkan untuk tidak berpuasa adalah setiap penyakit yang melampaui batas kesehatan seseorang. Atau menurut perkiraannya bahwa puasa akan menambah parah penyakitnya, atau dapat menunda masa kesembuhannya. ${ }^{23}$

\section{f. Berobat Dengan khamar}

Khamar tergolong najis. Tentang berobat dengan khamar ini terdapat dua pendapat:

1) Berobat dengan khamar. Pendapat ini dipopulerkan oleh fuqaha' Hanafiyah, Syafi'iyah ( $f i$ qaulin marjûh) dan madzhab Zhahiriyah dengan syarat-syarat sebagai berikut: ${ }^{24}$

a) Diyakini secara pasti bahwa khamar tersebut akan mendatangkan kesembuhan.

b) Informasi tersebut bersumber dari dokter muslim yang taat dan amanah.

c) Tidak ada obat lain yang dapat mengganti posisinya ('adamu wujûd al-badîl).

d) Takarannya tidak lebih dari yang direkomendasikan oleh dokter (al-dharûrah tuqaddaru biqadarihâ).

e) Pengobatan dengan khamar tersebut tidak dimaksudkan untuk memperoleh kenikmatan syahwati.

f) Takaran yang dipakai untuk obat tidak sampai memabukkan

${ }^{23}$ Ibnû Ryusd, Bidâyah al-Mujtahîd, jilid 1, hal. 295.

${ }^{24}$ Ibn Abidin, Muhammad Amin. 1421 H. Hasyiyah Rad al-Mukhtar 'ala alDur al-Mukhtar Syarah Tanwinal-Absar fi Fiqhi Madzhab al-Imam Abi Hanifah alNu'man. Jilid 6 (Beirut: Dâr al-Fikr). H 389. Dan Al-Bâbartî, Muhammad Ibn Muhammad. Tt. al-'Inâyah Syarh al-Hidâyah. Jilid 8 (Beirut: Dâr al-Fikr). hal 500.

Jurnal Ilmiah Al QALAM, Vol. 11, No. 23, Januari-Juni 2017 
H. Mahmudin, Lc., M.H: Rukhsah (Keringan) Bagi Orang Sakit Dalam Perspektif Hukum Islam

Argumen mereka bersumber dari al-Qur'an, Sunnah dan qiyas. Al-Qur'an misalnya dalam Surat al-An'âm ayat/ 6: 119.

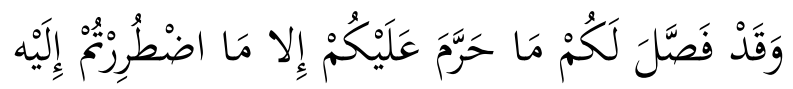

Artinya: "Padahal Sesungguhnya Allâh telah menjelaskan kepada

kamu apa yang diharamkan-Nya atasmu, kecuali apa yang terpaksa kamu memakannya".

Ayat ini lah yang menyatakan bahwa keadaan orang sakit berada pada situasi darurat sehingga ia boleh minum khamar sebagai obat. ${ }^{25}$

2. Tidak diperbolehkan berobat dengan khamar.

Pendapat ini dikemukakan oleh fuqha' Hanafiyah, Malikiyah, Syafi'iyah (qaulun râjih), dan Hanabilah dengan berbagai argumentasi dari al-Qur'an, al-Sunnah dan âtsâr para sahabat yang dapat dibaca secara detail di dalam karya-karya mereka. $^{26}$

3. Boleh bagi orang sakit untuk melakukan hal-hal yang dilarang pada saat berihram.

Bagi orang yang berihram dilarang melakukan hal-hal berikut: Mencukur rambut, memotong kuku, menutup kepala dengan penutup yang melekat di kepala, memakai pakaian yang berjahit bagi laki-laki dengan sengaja pada seluruh badan atau sebagiannya berupa baju /pakaian yang menutupi setiap

${ }^{25}$ Ibn Hazm, Ali Ibn Ahmad. Tt. al-Muhallâ, Tahqîq Ahmad Muhammad Syâkir. Jilid 1 (Beirut: Dâr al-Fikr. Tt). hal. 177.

${ }^{26}$ Ibn Abidin, Muhammad Amin.. Hasyiyah Rad al-Mukhtar 'ala al-Dur alMukhtar Syarah Tanwinal-Absar fi Fiqhi Madzhab al-Imam Abi Hanifah alNu'man.jilid 6 (Beirut: Dâr al-Fikr, 1421 H). h. 389. Al-Bâbartî, Muhammad Ibn Muhammad.. al- 'Inâyah Syarh al-Hidâyah.jilid 8 (Beirut: Dâr al-Fikr, Tt), hal. 500.

Jurnal Ilmiah Al QALAM, Vol. 11, No. 23, Januari-Juni 2017 
H. Mahmudin, Lc., M.H: Rukhsah (Keringan) Bagi Orang Sakit Dalam Perspektif Hukum Islam

pergelangan dari tubuh, seperti: gamis, celana, kaos kaki, kaos tangan dan lain-lain.

Para ulama sepakat bahwa orang yang sakit mendapat rukhsah (keringanan) untuk melakukan hal yang dilarang tersebut seperti bolehnya bagi laki-laki memakai pakain yang berjahit, tetapi dia harus membayarnya dengan membayar fidyah.

Adapun dalilnya adalah firman Alah Swt Q.S. alBaqarah: 2/196.

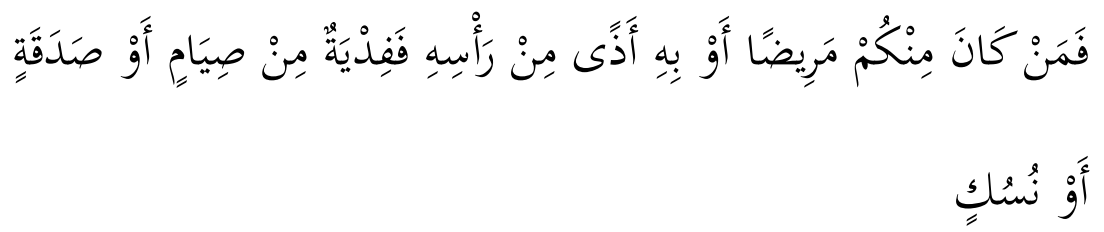

Artinya: "jika ada di antaramu yang sakit atau ada gangguan di kepalanya (lalu ia bercukur), Maka wajiblah atasnya berfid-yah, Yaitu: berpuasa atau bersedekah atau berkorban".

Hal ini juga diperkuat dengan hadis dari Ka'ab bin 'Ajah mengatakan: Aku mendapatkan gangguan dikepalaku, lalu aku dibawa kepada kepada Rasulullah Saw sedangkan kutu-kutu bertebaran di kepalaku lalu Rasulullah Saw bersabda

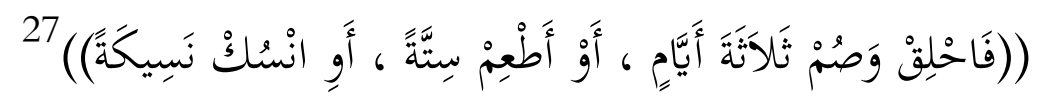

27 Al-Bukhâry, Shahih al-Bukhâry jilid 3, h. 13. Dan Muslim, Shahih Muslim, jilid 4, hal. 20.

Jurnal Ilmiah Al QALAM, Vol. 11, No. 23, Januari-Juni 2017 
H. Mahmudin, Lc., M.H: Rukhsah (Keringan) Bagi Orang Sakit Dalam Perspektif Hukum Islam

Artinya: "Cukurlah rambutmu dan puasa lah tiga hari atau memberi makan enam orang miskin atau berkorbanlah".

\section{Penutup}

Rukhsah (keringanan) yang diberikan oleh syariat Islam ini merupakan bukti bahwa syariat Islam adalah syariat yang mudah. Dan ini sudah menjadi tujuan adanya syariat ini untuk kemaslahatan umat manusia. Dalam penjelasan tentang rukhsah bagi orang yang sakit ini diharapkan tidak ada lagi alasan untuk meninggalkan ibadah yang diwajibkan kepada seorang hamba.

Secara umum Rukhsah (keringanan) bagi orang sakit sebagai brikut:

1. Bertayamum.

2. Suci darah istihadah, demikian juga bagi orang yang selalu dalam keadaan berhadas seperti, kencing tidak lancar, sering keluar angin atau madzi.

3. Minta bantuan orang lain untuk bersuci.

4. Melakukan Salat dengan cara yang mampu dia lakukan seperti berdiri, duduk, berbaring atau dengan isyarat.

5. Gugur kewajiban Salat berjamaah dan Salat Jumat.

6. Menjama' salat.

7. Berbuka puasa apabila puasa tersebut membahayakan dirinya.

8. Boleh melakukan sebagian yang diharamkan seperti memakai pakaian yang berjahit ketika berihram bagi laki-laki.

9. Boleh berobat dengan najis.

10. Boleh mewakilkan pelaksaan ibadah haji kepada orang lain.

11. Boleh membuka aurat untuk kepentingan berobat.

12. Gugur kewajiban berjihad (berperang).

13. Penundaan hukuman bagi orang sakit sampai dia sembuh.

Jurnal Ilmiah Al QALAM, Vol. 11, No. 23, Januari-Juni 2017 
H. Mahmudin, Lc., M.H: Rukhsah (Keringan) Bagi Orang Sakit Dalam Perspektif Hukum Islam

\section{DAFTAR PUSTAKA}

Adnan Muhammad 'Amâmah, Al-Ihkâm wa Takrîr (Beirut: Muasasah al-Risâlah, 2004 M)

Al-Bâbartî, Muhammad Ibn Muhammad. al-'Inâyah Syarh al-Hidâyah, (Beirut: Dâr al-Fikr, Tt)

Al-Bukhâry, Abdul 'Aziz bin Muhammad. Ushul Fakhru al-Islam bî Hâmisy Kasyful Asyrar. Jilid. 4. Beirut: Dâr al-Kitâb al-'Araby. 1974.

Al-Bukhâry, Muhammad bin Ismail, Shahîh al-Bukhâry, Beirut: Dâr alJail, t.th.

Al-Jurjânîy, Ali bin muhammad. al-Ta'rîfât. Teheran: Dâr Kutub al'Ilmiyah. t.th.

Al-Kâsany, 'Alauddin bin Mas'ud. Badâ'iu Shanâ'i. cet. II. Dâr alKitâb al-'Arab Lebanon: Beirut. 1982 M.

Al-Qarâfy, Syihabuddin Ahmad bin Idris. al- Furuq. Beirut: 'Alim alKitab, t.th.

As-Suyûthi, Jalal ad-Dîn Abdurrahman., al-Asybah wa an-Nazdair. Beirut: al-Maktabah asy-'Ariyah. 2003.

As-Syafi'i Muhammad bin Idris, al- 'Um. Beirut: Dâr Ma'rifah. t.th.

As-Syairâzy. al-Muhazdab fî Fiqh al-Imâm as-Syâfi'i i. Beirut: Dâr alMa'rifah. t.th.

At-Taftâzâny, Sa'du ad-dîn. Syarah at-Tawdhih 'Ala Matn at-Tanqîh. Beirut: Dâr al-Kutûb al-'Ilmiyah. t.th.

Ibn 'Abdi Salam, Izzuddin Abdul Aziz. Qawâed al-Ahkâm fî mashâlih al-Anam. Beirut: Dâr al-Kutûb al-'Ilmiyah. t.th.

Ibn Abidin, Muhammad Amin. Hasyiyah Rad al-Mukhtar 'ala al-Dur al-Mukhtar Syarah Tanwinal-Absar fi Fiqhi Madzhab al-Imam Abi Hanifah al-Nu'man (Beirut: Dâr al-Fikr, 1421 H.)

Ibn Hazm, Ali Ibn Ahmad. Tt. al-Muhallâ, Tahqîq Ahmad Muhammad Syâkir. Jilid 1 (Beirut: Dâr al-Fikr. Tt)

Ibnu Majah, Muhammad bin Yazid. Sunan Ibnu Majah. Beirut: alMaktabah al-'Ilmiah. t.th.

Jurnal Ilmiah Al QALAM, Vol. 11, No. 23, Januari-Juni 2017 
H. Mahmudin, Lc., M.H: Rukhsah (Keringan) Bagi Orang Sakit Dalam Perspektif Hukum Islam

Ibnu Manzûr. Lisan al-'Arab. Qaherah: al-Mu'asasah al-Mhisriyah. t.th.

Imam Malik, Al-Mudawanah al-Kubrâ, ( Mathba'ah Sa'ada, t.th)

Muhammad bin Ahmad Al-Qhurtuby, al-Jâmi' lî al-Ahkâm al-Quran, Beirut: Dâr Ihyâ at-Turâts, 1952M.

Muslim, Abû al-Hasan Muslim bin al-Hajâj. al-Jâmi' as-Shahîh. t.ket.

Sulaiman bin al-Asy'as Abû Dâud, Sunan Abî Dâud, jilid 1, (Beirut: Dâr al-Fikr, t.th)

http://bahasa.cs.ui.ac.id/kbbi/kbbi.php?keyword=sakit\&varbidang=all\& vardialek=all \&varragam $=$ all $\&$ varkelas $=$ all $\&$ submit $=$ tabel $/ 18$ November 2014, 20:30 PM

http://haegi13.wordpress.com/2014/03/22/sakit-menurut-para-ahli/18 November 2014, 20:30 PM. 